\title{
Fungal infection and aflatoxin contamination in maize collected from Gedeo zone, Ethiopia
}

\author{
Nitin M. Chauhan ${ }^{*}$, Alemayehu P. Washe and Tesfaye Minota
}

\begin{abstract}
Aflatoxins contamination of maize exhibits a serious threat to human and animal health over the past few decades. To protect the safety of food commodities, regular monitoring for afltoxins in food is necessary. In the proposed study, we have followed a rapid and sensitive biosensor approach as well as thin layer chromatography method for quantification of aflatoxins. Our data demonstrate that all the samples tested were beyond the safety level of aflatoxins as determined by Food and Drug Administration and European Union. Results of fungal mycoflora evidenced the massive presence of Aspergillus species (75\%) followed by Fusarium (11\%), Penicillium (8\%) and Trichoderma (6\%) as characterized by biochemical and sporulation properties. Use of internationally developed biosensor for detection of fungal toxin in this work is the first approach that was utilized in the developing country like Ethiopia. In the end, we conclude that fungal contaminant and there metabolites are potential threat to the agricultural industry and require urgent intervention.
\end{abstract}

Keywords: Mycotoxins, Biosensor, Cancer, Aspergillus, Thin layer chromatography

\section{Background}

Mycotoxins i.e. aflatoxins represents the class of fungal polyketide secondary metabolites which are mainly produced by two fungi viz. Aspergillus flavus and Aspergillus parasiticus (Bennett and Klich 2003). Both the fungi are reported to produce four principle kinds of aflatoxins i.e. aflatoxin $B_{1}\left(A F B_{1}\right)$, aflatoxin $B_{2}\left(A B_{2}\right)$, aflatoxin $\mathrm{G}_{1}\left(\mathrm{AFG}_{1}\right)$ and aflatoxin $\mathrm{G}_{2}\left(\mathrm{AFG}_{2}\right)$. Among these four classes of aflatoxins, $\mathrm{AFB}_{1}$ is predominant in nature and functionally carcinogenic in animal models if the toxicity exceeds threshold level (CAST 2003; Bennett and Klich 2003). The agricultural commodities that are prone to aflatoxins toxicity are corn and corn products, peanuts, cottonseed, milo, animal feed and majority of tree nuts (Beatriz et al. 2005; Binder et al. 2007). Aflatoxins toxicity has always remained a topic of debate in terms of international market as well as economic development of country which are part of trade market. To overcome these

\footnotetext{
*Correspondence: nitinchauhan25@gmail.com College of Natural and Computational Sciences, Dilla University, P.O. Box 419, Dilla, Ethiopia
}

challenges many countries have set maximum acceptable levels of aflatoxins in food and food products and animal feed (Diener et al. 1987; European Commission 2006).

Previous studies proposed that the occurrence of aflatoxins in food products mainly influenced by favorable conditions such as high moisture content and temperature (Wu et al. 2011). The extent of contamination by aflatoxins also varies with different geographic location, agricultural and agronomic practices, storage condition of crops and more importantly processing of food materials under favorable temperature and humidity conditions (Chauhan et al. 2008). In many developing countries of Africa continent, aflatoxins toxicity of food have been companion with increase risk of hepatocellular carcinoma in the presence of hepatitis B virus infection (Henry et al. 1999) and esophageal cancer respectively (Wild and Turner 2002). Intensive exposures of AFB1 at a concentration in excess of $2 \mathrm{ppm}$ are reported to cause non-specific liver problems and death within few days. Whereas, chronic effect of $\mathrm{AFB}_{1}$ leads to immunosuppression and nutritional deficiency (Peraica et al. 1999). 
Maize as an agricultural commodity is considered as one of the best substrate for the fungi to grow and produce toxicogenesis. Many surveys across the globe showed that this crop can be highly contaminated with aflatoxins (Munkvold 2003). Ethiopia crop agriculture is very complicated, involving substantial alteration in crops cultivated around the different parts of country (Chilot et al. 1998). The maize crop is third most important crop in Ethiopia after wheat and teff and accounts for largest share in total crop production (Befekadu and Berhanu 2000). Production of maize sharply expanded from 2.5 million tons in 2003-2004 to 8 million tons in 2012-2013 (Bonger et al. 2004). Maximum quantities of maize produced are stored under poor and unsatisfactory storage conditions for considerable period of time. Traditional storage of maize in Ethiopia is like made up of mud, bamboo strips, and pits. In comparison of these storage conditions, recent technology involves storage of maize in polyethylene bags and gunny bags (Anjum et al. 2012). Previous reports proposed that extended storage of maize under unacceptable storage conditions enhances fungal growth which promotes the production of respective mycotoxins (Chauhan et al. 2008).

Despite the fact that maize is a crucial food to Ethiopian population and is vulnerable to mycotoxins risk due to different geographical and climatic conditions and poor handling of crop and storage, limited surveys have been reported on the relation of fungal mycotoxins in the crop and ways to protect the food from contamination in Ethiopia (Alemu 2008). Therefore the aim of the proposed work is to determine the fungal load of maize sample from Dilla region of Ethiopia and quantify the concentration of aflatoxins by using rapid and sensitive technique. In the present study, we used an immunochromatographic assay and thin layer chromatography assay for quantification of aflatoxin in maize samples. Thus, use of internationally developed biosensor for detection of aflatoxins in this work is the first approach that was developed in the developing countries like Ethiopia and results are discussed below.

\section{Methods}

\section{Materials}

Reveal Q+ aflatoxin test kit (Lot No. 203322, Neogen Corporation, USA) was used for quantitative analysis of aflatoxins in maize. Mycotoxin biosensor was purchased from Mobile Assay Inc., 150 Murray Street, PO Box 96, Nowot with Wireless Nexus 7 inch Tablet inbuilt with Android 4.0 operating system, GPS tracking and mReader Software for measuring the intensity of band developed on Reveal Q+ Aflatoxin Test Strips (Neogen Corporation, USA). The assay is based on single-step lateral flow immunocharomatographic principle with competitive immunoassay format (Mobile Assay Inc; Neogen Corporation, USA).

\section{Analytical standard chemicals}

Different standards of aflatoxins were obtained from HiMedia Laboratories Ltd. Mumbai, India. Preparation of standard solution was done by referring to the Manual of Official Methods of Analysis of Association of Official Analytical Chemists (AOAC 1995). From the stock solutions of each toxin as determined by UV-Spectrophotometer (UV1800, Shimadzu, Japan), a working standard of 25, 50, 75, $100,125,150$, and $200 \mathrm{ppb}$ for $\mathrm{AFB}_{1}, \mathrm{AFB}_{2}, \mathrm{AFB}_{3}$ and $\mathrm{AFB}_{4}$ was prepared in benzene: acetonitrile $(98: 2 \mathrm{v} / \mathrm{v})$ solution. All the media components and chemicals were purchased from Hi-Media Laboratories Ltd. Mumbai, India.

\section{Study site}

The study was carried out in Dilla town of Gedeo zone located in South Nations Nationalities and Peoples Region (SNNPR) of south Ethiopia. The place is located at $86 \mathrm{~km}$ from regional capital Hawassa and $359 \mathrm{~km}$ from nation capital Addis Ababa. Five different Gedeo zones namely Dilla Zuria, Yirgachaffe, Kochere, Qisha and Wonago were visited for collection of maize samples.

\section{Sampling}

A total number of 150 different maize samples were collected from different Gedeo zones as stated above. All the samples were randomly selected from local markets, store house, flour mills, grain retailers and street corn fruit seller. Commodities samples included dry maize flour, freshly harvested corn fruits and dry maize kernels (Table 1).

\section{Sample preparation and aflatoxin quantification Aflatoxin quantification by using biosensor based immunochromatographic assay}

The aflatoxins were extracted as per manufactures protocol (Mobile Assay Inc; Neogen Corporation, USA). Briefly, different samples were bring to laboratory and grind or paste so at least $75 \%$ of material passes through a 20 mesh sieve, about the particle size of fine instant coffee. Aflatoxins were extracted by mixing 1 part of sample to 5 parts of $65 \%$ ethanol (HPLC grade, HI-Media Laboratories Ltd. Mumbai, India) and were vigorously vortex for $3 \mathrm{~min}$. The samples were allowed to settled and then filter with syringe filter and finally utilized for quantification of aflatoxins by using Reveal Q+ aflatoxin test strip (Neogen Corporation, USA).

\section{Quantification of aflatoxin by using thin layer chromatography}

Quantification of aflatoxin was done according to the methodology described previously (Soares and 
Table 1 Distribution of maize samples on the basis of location and types

\begin{tabular}{lllcl}
\hline Sample matrix & Sample location & Sample code & Number of samples & $\begin{array}{l}\text { Percentage of samples } \\
\text { from total samples }\end{array}$ \\
\hline Dry maize flour & Dilla Zuria & MS1-MS26 & 26 & 39 \\
& Yirgachaffe & MS56-MS70 & 15 & 23 \\
& Kochere & MS86-MS98 & 13 & 20 \\
& Qisha & MS107-MS113 & 7 & 11 \\
& Wonago & MS136-MS139 & 4 & 6 \\
Freshly harvested corn fruit & Dilla Zuria & MS27-MS47 & 21 & 32 \\
& Yirgachaffe & MS71-MS79 & 9 & 14 \\
& Kochere & MS99-MS104 & 6 & 9 \\
& Qisha & MS114-MS124 & 11 & 17 \\
Dry maize kernels & Wonago & MS140-MS146 & 7 & 11 \\
& Dilla Zuria & MS48-MS55 & 8 & 12 \\
& Yirgachaffe & MS80-MS85 & 6 & 9 \\
& Kochere & MS105-MS106 & 2 & 17 \\
\hline
\end{tabular}

All the samples were randomly selected from local markets, store house, flour mills, grain retailers and street corn fruit seller from different location as shown in table

Rodriguez-Amaya 1989) by using thin layer chromatography. Briefly, 50 grams of sample were homogenized in a blender containing a solution mixture of $270 \mathrm{ml}$ of methanol and $30 \mathrm{ml}$ of potassium chloride for $5 \mathrm{~min}$. The mixture was filtered using Whatmann filter paper. $150 \mathrm{ml}$ of filtrate was transferred to a glass containing a solution mixture of $150 \mathrm{ml}$ of $30 \%$ ammonium sulfate and $50 \mathrm{ml}$ of Celite. Again the mixture was filter using Whatmann filter paper. $150 \mathrm{ml}$ of filtrate was transferred to a separating funnel and was filled with $150 \mathrm{ml}$ of water and twice partitioned with $10 \mathrm{ml}$ of chloroform. $5 \mathrm{ml}$ of solution from both the chloroform partition were combined. The mixture was evaporated in a water bath at $80^{\circ} \mathrm{C}$. The extract was spotted along with working standards with the use of Autospotter on TLC plate (Silica Gel 60G, Merck). The plate was developed in an unsaturated tank containing toluene-ethyl acetatechloroform-formic acid (70:50:50:20, v/v). The aflatoxins were visualized by the incidence of UV light. For quantification of afttoxin, known volume of samples and standards were applied to TLC plate. The plates were developed as described above in the respective solvent. All calculations were done according to the manual of to the Manual of Official Methods of Analysis of AOAC (AOAC 1995). The identity of aflatoxins was also confirmed by reaction with its derivatives i.e. trifluoroacetic acid according to Przybykski (1975).

\section{Determination of fungal species and population}

To detect the presence of fungi in maize samples fungal bioassay was done. Briefly, twenty gram of each sample was dissolved in $180 \mathrm{ml}$ of sterile saline solution. One $\mathrm{ml}$ of above solution was aseptically spread on Potato Dextrose Agar (Hi-Media Laboratories Ltd. Mumbai, India) and plates were incubated at $30{ }^{\circ} \mathrm{C}$ for 7 days and After incubation they were identified to genus and species level according to taxonomic keys and guides available for the kingdom fungi (Pitt and Hocking 2009).

\section{Statistical analysis}

The differences in aflatoxins concentration in maize between the Gedeo zones, Ethiopia were compared by ANOVA in PAST 3.11 software (Hammer et al. 2001). $P<0.05$ was considered statistically significant.

\section{Results}

\section{Aflatoxins contamination of maize samples}

All the maize samples intended for human consumption tested by us shown aflatoxins toxicity higher than those recommended by Food and Drug Administration (FDA) and European Union (EU) regulatory levels as determined by immunochromatographic assay and thin layer chromatography. Results of immunochromatographic assay reveal that mean aflatoxins concentration for all samples was observed as $53 \mathrm{ppb}$. Out of total 150 numbers of samples, $53 \%$ (80 samples) possesses more than $50 \mathrm{ppb}$ concentration of aflatoxins while, $38 \%$ (57 samples) have the aflatoxins level of $40-50 \mathrm{ppb}$. In the remaining $9 \%$ (13 samples), aflatoxins concentration was found to be in the range of 20-40 ppb (Table 2). Whereas, results of thin layer chromatography demonstrated $52.1 \mathrm{ppb}$ as a mean aflatoxin concentration for all 150 samples tested. Among 150 samples tested, $56 \%$ 
Table 2 Concentrations of aflatoxins contaminated maize samples as determined by immunochromatographic assay

\begin{tabular}{|c|c|c|c|c|c|}
\hline Sample no. & $\begin{array}{l}\text { Concentration } \\
\text { of aflatoxins (ppb) }\end{array}$ & Sample no. & $\begin{array}{l}\text { Concentration } \\
\text { of aflatoxins ( } \mathrm{ppb} \text { ) }\end{array}$ & Sample no. & $\begin{array}{l}\text { Concentration } \\
\text { of aflatoxins ( } \mathrm{ppb} \text { ) }\end{array}$ \\
\hline MS1 & 40.2 & MS26 & 46.8 & MS51 & 34.23 \\
\hline MS2 & 38.6 & MS27 & 50.67 & MS52 & 44.08 \\
\hline MS3 & 40.71 & MS28 & 33.49 & MS53 & 43.28 \\
\hline MS4 & 43.21 & MS29 & 47.07 & MS54 & 43.59 \\
\hline MS5 & 43.73 & MS30 & 51.78 & MS55 & 64.7 \\
\hline MS6 & 39.94 & MS31 & 55.26 & MS56 & 50.29 \\
\hline MS7 & 57.7 & MS32 & 60.29 & MS57 & 41.86 \\
\hline MS8 & 56.9 & MS33 & 49.53 & MS58 & 51.62 \\
\hline MS9 & 43.38 & MS34 & 48.13 & MS59 & 80.98 \\
\hline MS10 & 47.35 & MS35 & 54.45 & MS60 & 79.26 \\
\hline MS11 & 50.23 & MS36 & 63 & MS61 & 77.67 \\
\hline MS12 & 43.48 & MS37 & 43.9 & MS62 & 88.47 \\
\hline MS13 & 45.38 & MS38 & 43.77 & MS63 & 66.5 \\
\hline MS14 & 32.34 & MS39 & 50.48 & MS64 & 83.23 \\
\hline MS15 & 74.09 & MS40 & 43.04 & MS65 & 53.77 \\
\hline MS16 & 47.11 & MS41 & 38.45 & MS66 & 66.55 \\
\hline MS17 & 52.25 & MS42 & 41.8 & MS67 & 49.19 \\
\hline MS18 & 53.12 & MS43 & 61.24 & MS68 & 44.14 \\
\hline MS19 & 47.4 & MS44 & 38.14 & MS69 & 45.4 \\
\hline MS20 & 54.84 & MS45 & 45.61 & MS70 & 51.74 \\
\hline MS21 & 44.96 & MS46 & 43.29 & MS71 & 53.76 \\
\hline MS22 & 50.14 & MS47 & 43.44 & MS72 & 73.49 \\
\hline MS23 & 60.25 & MS48 & 42.6 & MS73 & 83.7 \\
\hline MS24 & 45.48 & MS49 & 46.09 & MS74 & 43.1 \\
\hline MS25 & 52.52 & MS50 & 53.53 & MS75 & 42.49 \\
\hline MS76 & 45.65 & MS101 & 53.26 & MS126 & 45.12 \\
\hline MS77 & 53.04 & MS102 & 50.35 & MS127 & 43.88 \\
\hline MS78 & 54.64 & MS103 & 60.89 & MS128 & 45.02 \\
\hline MS79 & 67.87 & MS104 & 59.96 & MS129 & 46.9 \\
\hline MS80 & 64.1 & MS105 & 46.72 & MS130 & 54.6 \\
\hline MS81 & 59.19 & MS106 & 47.93 & MS131 & 43.77 \\
\hline MS82 & 45.33 & MS107 & 41.7 & MS132 & 91.04 \\
\hline MS83 & 44.66 & MS108 & 61.74 & MS133 & 59.07 \\
\hline MS84 & 43.46 & MS109 & 90.4 & MS134 & 44.67 \\
\hline MS85 & 56.5 & MS110 & 57.47 & MS135 & 59.7 \\
\hline MS86 & 50.94 & MS111 & 62.52 & MS136 & 81.31 \\
\hline MS87 & 31.61 & MS112 & 53.82 & MS137 & 70.2 \\
\hline MS88 & 43.42 & MS113 & 53.78 & MS138 & 64.51 \\
\hline MS89 & 38.4 & MS114 & 51.79 & MS139 & 86.28 \\
\hline MS90 & 67.22 & MS115 & 59.49 & MS140 & 91.4 \\
\hline MS91 & 44.04 & MS116 & 53.08 & MS141 & 59.05 \\
\hline MS92 & 91.4 & MS117 & 50.75 & MS142 & 49.35 \\
\hline MS93 & 51.08 & MS118 & 52.38 & MS143 & 38.11 \\
\hline MS94 & 60.9 & MS119 & 49.4 & MS144 & 33.07 \\
\hline MS95 & 33.68 & MS120 & 59.1 & MS145 & 57.17 \\
\hline MS96 & 43.47 & MS121 & 53.55 & MS146 & 41.21 \\
\hline MS97 & 55.28 & MS122 & 47.91 & MS147 & 56.87 \\
\hline MS98 & 50.42 & MS123 & 54.7 & MS148 & 28.24 \\
\hline MS99 & 68.38 & MS124 & 47.81 & MS149 & 51.69 \\
\hline
\end{tabular}


Table 2 continued

\begin{tabular}{|c|c|c|c|c|c|}
\hline Sample no. & $\begin{array}{l}\text { Concentration } \\
\text { of aflatoxins (ppb) }\end{array}$ & Sample no. & $\begin{array}{l}\text { Concentration } \\
\text { of aflatoxins (ppb) }\end{array}$ & Sample no. & $\begin{array}{l}\text { Concentration } \\
\text { of aflatoxins (ppb) }\end{array}$ \\
\hline MS100 & 66.57 & MS125 & 45.41 & MS150 & 47.49 \\
\hline
\end{tabular}

Aflatoxins concentrations were quantified by using mReader Software by measuring the intensity of band developed on Reveal Q+ aflatoxin test strips. Detection limit for aflatoxins was $2-150 \mathrm{ppb}$

(84 samples) possesses aflatoxin concentration more than $50 \mathrm{ppb}$. While, $28 \%$ (42 samples) showed aflatoxin concentration in the range of $40-50 \mathrm{ppb}$ and $16 \%$ (24 samples) has aflatoxin concentration in the range of 20-40 ppb (Table 3). There was no significant differences were observed in the different maize commodities as well as no correlation with different locality devoid of the two different methodologies used for quantification of aflatoxin in this study $(P=0.567)$. Average aflatoxins concentration for dry maize flour, corn fruit and dry maize seeds resulted in 53.89, 52.47 and 49.79 ppb respectively as determined by immunochroatographic assay (Table 2). While mean concentrations of aflatoxins for dry maize flour, corn fruit and dry maize seeds were found to be $54.86,50.87$ and $48.29 \mathrm{ppb}$ as determined by thin layer chromatography (Table 3 ).

\section{Fungal mycoflora of different maize samples}

The different load for fungal mycoflora of maize samples from Dilla region is highlighted in Fig. 1. Identification of fungal strain by standard protocol revealed that Aspergillus genus was predominant among maize samples which accounts for 75 \% (113 samples). Among Aspergillus species, A. flavus accounts for $64 \%$ (96 samples) followed by $A$. parasiticus with a frequency of $11 \%$ (17 samples). Apart from Aspergillus fungi, Fusarium spp, Penicillium spp and Trichoderma spp were also isolated among various maize samples studied. Fusarium spp contamination contributed $11 \%$ (17 samples) while, Penicillium spp and Trichoderma spp shares $8 \%$ (12 samples) and $6 \%$ (8 samples) respectively (Fig. 1).

\section{Discussion}

Aflatoxins contamination of crops possesses a serious threat to human and animal health as well as consider as danger in trade market (Bennett and Klich 2003). Among various mycotoxins produced by fungus, aflatoxins has distinct relation with maize requires serious concerns in decontamination of toxicity in many agricultural commodities (Trung et al. 2008). Even though maize in one of the most important crop than wheat and teff in Ethiopia, maize are not well studied for the toxicity generated by aflatoxins. Aflatoxins are reported to be prevalent through the west and east Africa. Some of the previous studies reported that $90 \%$ of east African maize samples showed the evidence of high level of aflatoxins, and some parts of West Africa the exposure of aflatoxins is as high as 99 \% (Doko et al. 1995; Shephard 2004; Rodrigues et al. 2011). In comparison to east and West Africa, Ethiopia has a serious problem with aflatoxins though the exact levels of exposures are uncertain due to lack of data or testing (Bernard et al. 2008). In the proposed study, all the samples come from the regions within the temperature ranges from 20 to $31{ }^{\circ} \mathrm{C}$ (Alene et al. 2000). Earlier studies demonstrated that higher temperature supports the growth of Aspergillus species (Chauhan et al. 2008). In addition to the above factor, farmers are not aware of handling of crops and storage in this part of country. They did not follow the standards for the processing of maize samples. Therefore possibilities of contamination of food commodities employed for human consumption in this region cannot be ruled out. The results of our study confirmed that all the samples utilized in this study are at a risk of contamination of aflatoxins. As shown in Tables 2 and 3, more than $50 \%$ of samples possess aflatoxin concentration more than $50 \mathrm{ppb}$. In addition to this, the average mean concentration of aflatoxin was resulted as 53 and $52.1 \mathrm{ppb}$ as determined by immunochromatograhpic assay and thin layer chromatography respectively.

Aflatoxins not only support severe health risk but also favours significant economic lost to farmers whether their crops must be rejected or accepted for buyers. For example in Kenya, two World Food Program of the United Nation purchased maize samples were confiscated and destroyed because of the lack of acceptable levels of aflatoxins in the purchased crops (Hassan et al. 1998). This is of particular concerns to smallholder farmers as aflatoxins toxicity primarily emerge out where there is high moisture content and high temperatures which is supported by inadequate storage structures. The place visited in this study fulfils all of these criteria and was confirmed by our study that aflatoxins contamination is serious challenge to smallholder farmers especially in this part of country.

Previous studies from neighbouring countries of Ethiopia like Kenya, Somalia, Uganda and Sudan demonstrate that A. flavus and $A$. parasiticus can invade maize seed in the field before harvest, during post harvest, drying and curing as well as during storage and transportation. Since, spores 
Table 3 Concentrations of aflatoxins contaminated maize samples as determined by thin layer chromatography

\begin{tabular}{|c|c|c|c|c|c|}
\hline Sample no. & $\begin{array}{l}\text { Concentration } \\
\text { of aflatoxins (ppb) }\end{array}$ & Sample no. & $\begin{array}{l}\text { Concentration } \\
\text { of aflatoxins (ppb) }\end{array}$ & Sample no. & $\begin{array}{l}\text { Concentration } \\
\text { of aflatoxins } \\
\text { (ppb) }\end{array}$ \\
\hline MS1 & 43 & MS26 & 56 & MS51 & 35 \\
\hline MS2 & 36 & MS27 & 51 & MS52 & 44 \\
\hline MS3 & 51 & MS28 & 34 & MS53 & 36 \\
\hline MS4 & 44 & MS29 & 37 & MS54 & 44 \\
\hline MS5 & 39 & MS30 & 52 & MS55 & 65 \\
\hline MS6 & 45 & MS31 & 51 & MS56 & 52 \\
\hline MS7 & 57 & MS32 & 62 & MS57 & 49 \\
\hline MS8 & 57 & MS33 & 36 & MS58 & 52 \\
\hline MS9 & 35 & MS34 & 47 & MS59 & 78 \\
\hline MS10 & 48 & MS35 & 48 & MS60 & 76 \\
\hline MS11 & 52 & MS36 & 61 & MS61 & 81 \\
\hline MS12 & 48 & MS37 & 44 & MS62 & 85 \\
\hline MS13 & 55 & MS38 & 31 & MS63 & 62 \\
\hline MS14 & 36 & MS39 & 51 & MS64 & 83 \\
\hline MS15 & 75 & MS40 & 46 & MS65 & 54 \\
\hline MS16 & 48 & MS41 & 42 & MS66 & 65 \\
\hline MS17 & 59 & MS42 & 43 & MS67 & 43 \\
\hline MS18 & 57 & MS43 & 65 & MS68 & 31 \\
\hline MS19 & 37 & MS44 & 39 & MS69 & 35 \\
\hline MS20 & 55 & MS45 & 51 & MS70 & 52 \\
\hline MS21 & 45 & MS46 & 44 & MS71 & 54 \\
\hline MS22 & 52 & MS47 & 35 & MS72 & 74 \\
\hline MS23 & 63 & MS48 & 43 & MS73 & 81 \\
\hline MS24 & 46 & MS49 & 47 & MS74 & 43 \\
\hline MS25 & 55 & MS50 & 51 & MS75 & 31 \\
\hline MS76 & 45 & MS101 & 51 & MS126 & 46 \\
\hline MS77 & 53 & MS102 & 52 & MS127 & 44 \\
\hline MS78 & 51 & MS103 & 61 & MS128 & 45 \\
\hline MS79 & 68 & MS104 & 48 & MS129 & 48 \\
\hline MS80 & 64 & MS105 & 45 & MS130 & 51 \\
\hline MS81 & 59 & MS106 & 42 & MS131 & 44 \\
\hline MS82 & 56 & MS107 & 42 & MS132 & 81 \\
\hline MS83 & 48 & MS108 & 62 & MS133 & 52 \\
\hline MS84 & 37 & MS109 & 91 & MS134 & 41 \\
\hline MS85 & 51 & MS110 & 58 & MS135 & 60 \\
\hline MS86 & 51 & MS111 & 57 & MS136 & 79 \\
\hline MS87 & 30 & MS112 & 59 & MS137 & 75 \\
\hline MS88 & 41 & MS113 & 56 & MS138 & 61 \\
\hline MS89 & 32 & MS114 & 52 & MS139 & 87 \\
\hline MS90 & 64 & MS115 & 60 & MS140 & 82 \\
\hline MS91 & 47 & MS116 & 54 & MS141 & 60 \\
\hline MS92 & 86 & MS117 & 51 & MS142 & 51 \\
\hline MS93 & 54 & MS118 & 53 & MS143 & 35 \\
\hline MS94 & 62 & MS119 & 47 & MS144 & 32 \\
\hline MS95 & 34 & MS120 & 60 & MS145 & 51 \\
\hline MS96 & 38 & MS121 & 57 & MS146 & 42 \\
\hline MS97 & 56 & MS122 & 48 & MS147 & 51 \\
\hline MS98 & 52 & MS123 & 54 & MS148 & 20 \\
\hline
\end{tabular}


Table 3 continued

\begin{tabular}{llllll}
\hline Sample no. & $\begin{array}{l}\text { Concentration } \\
\text { of aflatoxins }(\mathbf{p p b})\end{array}$ & Sample no. & $\begin{array}{l}\text { Concentration } \\
\text { of aflatoxins (ppb) }\end{array}$ & $\begin{array}{l}\text { Sample no. } \\
\begin{array}{l}\text { Concentration } \\
\text { of aflatoxins } \\
\text { (ppb) }\end{array}\end{array}$ \\
\hline MS99 & 65 & MS124 & 42 & MS149 & 58 \\
MS100 & 69 & MS125 & 41 & MS150 & 48 \\
\hline
\end{tabular}

Aflatoxins concentrations were quantified by comparing with the standards developed on thin layer chromatography. Detection limit for aflatoxins was $2-200$ ppb

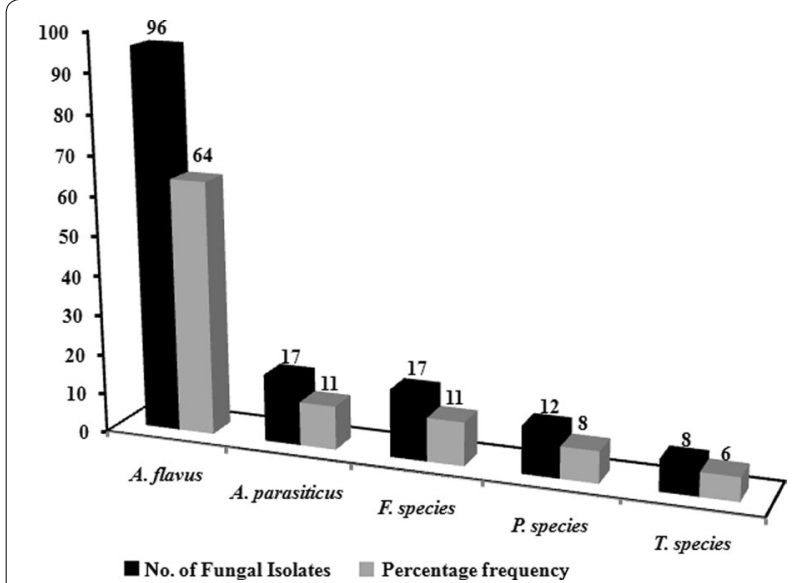

Fig. 1 Distribution of fungal mycoflora among maize samples from Dilla region, Ethiopia. One $\mathrm{ml}$ of sample solution was aseptically spread on Potato Dextrose Agar and plates were incubated at $30^{\circ} \mathrm{C}$ for 3-5 days. After incubation fungus were identified to genus and species level by referring standard protocol

of both the species can survive for a long period of time in air and can get disseminated over a long period of distance from one place to another (Bhat et al. 1997; Gao et al. 2007). Since, Dilla town is located on the Addis Ababa-Nairobi international highway, there is potential of dissemination of spores from Kenya to Ethiopian commercial outlets as well as in maize fields. Our data confirmed the presence of Aspergillus as dominant fungal mycoflora among all which accounts for $75 \%$ of samples followed by Fusarium (11\%), Penicillium (8\%) and Trichoderma (6\%) (Fig. 1).

The prevalence of contamination of maize sample in this study by aflatoxins is consistent with previous reports from this country (Abera and Admssu 1988; Habtamu and Kelbessa 2001) and in other countries with same climatic conditions (Shephard 2004). However within Ethiopia, a national standard has yet to be set the regulatory acceptable levels of aflatoxins. Therefore it is difficult to say that really the maize samples are acceptable or rejectable for human consumption base on our study. But in comparison to regulatory levels of aflatoxins with other countries the concentration of aflatoxins found in the samples of this study are quite higher when compared with their respective setting limits. Based on that we can recommend that maize samples analyzed in these findings correspond to heavier toxicity of aflatoxins and requires setting of safety levels for mycotoxins by respective bodies of the countries immediately.

Humans are exposed to aflatoxins mostly by consuming contaminated foods containing fungal metabolites at threshold levels. Most of the developing countries in Africa, risk of aflatoxins contamination have been companion with increase risk of hepatocellular carcinoma and esophageal cancer respectively (CAST 2003; Murugavel et al. 2007). Although there is no direct evidence still available that demonstrate that aflatoxins affected food consumption leads to cancer in Ethiopia. Therefore findings of these reports emphasize that the presence of aflatoxins at high concentration in maize samples may related to serious public health concerns and assured that fungal toxicity is a major problem in this country. Since no agricultural commodities are not directly prone to mycotoxins contamination, results of this work will guide the identification of various factors responsible for contamination and the areas where control measures requires serious intervention. Implementation of national prevention and control strategies like proper pre-harvest and pro-harvest treatment of infected maize and standard storage facilities are required to reduce the risk of aflatoxin contamination by fungi. In addition to this more studies are required from different parts of Ethiopia to generate data for Ethiopian government to work on policy making decision strategy. More importantly there is a need to find out whether aflatoxins are dominant among mycotoxins in maize or chances of contamination of other mycotoxins other than aflatoxins are prevalent. Since in our study, $25 \%$ of mycoflora was not Aspergillus but governed by other fungal species like Fusarium, Penicillium, Trichoderma that are known to produce different kinds of mycotoxins.

\section{Conclusions}

The maize samples collected from Gedeo zone, Ethiopia were contaminated with aflatoxins. Due to the levels of aflatoxins observed in this work posses a potential threat to the agricultural industry and require urgent intervention. It is important to undertake control strategies and to distinguish the maize samples whether suitable for human consumptions and animal feed or not. These 
results emphasize the need for future research to reduce the occurrence of aflatoxins contamination in Ethiopian maize.

\section{Authors' contributions}

NMC carried out all experimental work, data acquisition and analysis, literature search. He was also responsible for study concept, designing and coordinating the research and supervising the work. APW contributed to writing and manuscript preparation. TN carried our preliminary analysis and contributed to experiments. All authors read and approved the final manuscript.

\section{Acknowledgements}

The authors are thankful to Dilla University Research, Dissemination and Community Services Office for supporting the financed by a Grant for the proposed work.

\section{Competing interests}

The authors declare that they have no competing interests.

Received: 13 January 2016 Accepted: 1 June 2016

Published online: 17 June 2016

\section{References}

Abera G, Admssu M (1988) A survey of aflatoxin in maize, sorghum and teff samples. Ethiop J Health Dev 2:59-70

Alemu D (2008) Grain markets in Ethiopia: a literature review. United Nation Wold Food Program, Addis Ababa

Alene AD, Poonyth D, Hassan RM (2000) Determinants of the adoption and intensity of use of improved maize varieties in the central highlands of Ethiopia: a tobit analysis. Agrekon 39:633-643

Anjum MA, Khan SH, Sahota AW, Sardar R (2012) Assessment of aflatoxin B1 in commercial poultry feed and feed ingredients. J Anim Plant Sci 22:268-272

AOAC (1995) Official methods of analysis of the association of official analytical chemists, 16th edn. Method 971.22; 985.17. The Association, Arlington, Washington

Beatriz LS, Alessandra BR, Paulo AM, Miguel MJ (2005) Aflatoxins, ochratoxin A and zearalenone in maize-based food products. Braz J Microbiol 36:289-294

Befekadu D, Berhanu N (2000) Annual report on the Ethiopian economy, vol 1. The Ethiopian Economic Association, Addis Ababa

Bennett JW, Klich M (2003) Mycotoxins. Clin Microbiol Rev 16:497-516

Bernard T, Alemayehu S, Gabre-Madhin E (2008) Impact of co-operatives on smallholders' commercialization behaviour: evidence from Ethiopia. Agric Econ 39:147-161

Bhat RV, Sherry PH, Amruth RP, Sudershan RV (1997) A food borne disease outbreak due to the consumption of mouldy sorghum and maize containing fumonisis mycotoxins. J Toxicol 35:249-255

Binder EM, Tan LM, Chin LJ, Hadle J, Richard J (2007) Worldwide occurrence of mycotoxins in commodities feeds and feed ingredients. Anim Feed Sci Technol 137:265-282

Bonger T, Ayele G, Kumsa T (2004) Agricultural extension, adoption and diffusion in Ethiopia. Research report no. 1. Ethiopian Development Research Institute, Addis Ababa

Chauhan Y, Wright G, Rachaputi N (2008) Modelling climatic risks of aflatoxin contamination in maize. Aust J Exp Agric 48:358-366

Chilot Y, Shapiro BI, Mulat D (1998) Factors influencing adoption of new wheat technologies in Walmara and Addis Alem areas of Ethiopia. Ethiop J Agric Econ 1:63-84
Council for Agricultural Science and Technology (CAST) (2003) Mycotoxins: risks in plant, animal and human systems. Task Force Report No. 139, Ames, IA, USA

Diener U, Cole R, Sanders T, Payne G, Lee L, Klich M (1987) Epidemiology of aflatoxin formation by Aspergillus flavus. Ann Rev Phytopathol 25:249-270

Doko MB, Rapior S, Visconti A, Schjoth JE (1995) Incidence and levels of fumonisin contamination in maize genotypes grown in Europe and Africa. J Agric Food Chem 43:429-434

European Commission (EC) (2006) Commission Regulation (EC) No. 1881/2006 of 19 December 2006 setting maximum levels for certain contaminants in foodstuffs. Off J Eur Union L364:5-24

Gao J, Liu Z, Yu J (2007) Identification of Aspergillus section flavi in maize in northeastern China. Mycopathologia 11:91-95

Habtamu F, Kelbessa U (2001) Survey of aflatoxin contamination in Ethiopia. Ethiop J Health Sci 11:17-25

Hammer O, Harper DAT, Ryan PD (2001) PAST: paleontological statistics software package for education and data analysis. Palaeontol Electron 4:1-9

Hassan RM, Onyango R, Rutto JK (1998) Relevance of maize research in Kenya to maize production problems perceived by farmers. In: Hassan RM (ed) Maize technology development and transfer: a GIS approach to research planning in Kenya. CAB International, London

Henry SH, Bosch FX, Troxell TC, Bolger PM (1999) Reducing liver cancerglobal control of aflatoxin. Science 286:2453-2454

Mobile Assay Inc, Neogen Corporation, Lansing, USA. http://www.mobileassay. com

Munkvold GP (2003) Cultural and genetic approaches to managing mycotoxins in maize. Ann Rev Phytopathol 41:99-116

Murugavel KG, Naranatt PP, Shankar EM, Mathews S, Raghuram K, Rajasambandam P, Jayanthi V, Surendra R, Murali A, Srinivas U, Palaniswamy KR, Srikumari D, Thyagarajan SP (2007) Prevalence of aflatoxin B1 in liver biopsies of proven hepatocellular carcinoma in India determined by an in-house immunoperoxidase test. J Med Microbiol 56:1455-1459

Neogen Corporation. Mycotoxin handbook. 3rd edn. http://www.neogen. com/FoodSafety/pdf/MycotoxinHandbook_12.pdf

Peraica M, Radic B, Lucic A, Pavlovic M (1999) Toxic effects of mycotoxins in human health. Bull WHO 77:754-766

Pitt Jl, Hocking AD (2009) Fungi and food spoilage, 3rd edn. Springer, New York Przybykski W (1975) Formation of aflatoxin derivatives on thin layer chromatographic plates. J Assoc Anal Chem 58:163-164

Rodrigues I, Handl J, Binder EM (2011) Mycotoxin occurrence in commodities, feeds and feed ingredients sourced in the Middle East and Africa. Food Add Cont Part B Surveill 4:168-179

Shephard GS (2004) Mycotoxins worldwide: current issues in Africa. In: Barug D, van Egmond H, Lopez-Garcia R, van Ossenbruggen T, Visconti A (eds) Meeting the Mycotoxin Menace. Wageningen Academic Publishers, Wageningen, pp 81-88

Soares LMV, Rodriguez-Amaya DB (1989) Survey of aflatoxins, ochratoxin A, zearalenone, and sterigmatocystin in some Brazilian foods by using multi-toxin thin-layer chromatographic method. J Assoc Off Anal Chem $72: 22-26$

Trung TS, Tabuc C, Bailly S, Querin A, Guerre P, Bailly JD (2008) Fungal mycoflora and contamination of maize from Vietnam with aflatoxin B1 and fumonisin B1. World Mycotox J 1:87-94

Wild CP, Turner PC (2002) The toxicology of aflatoxins as a basis for public health decisions. Mutagenesis 17:471-481

Wu F, Bhatnagar D, Bui-Klimke T, Carbone I, Hellmich R, Munkvold G, Paul P, Payne G, Takle E (2011) Climate change impacts on mycotoxin risks in US maize. World Mycot J 4:79-93 